\title{
Design and Analysis of the Rotatable Balance-arm System in Crane
}

\author{
Jian Qin ${ }^{1, a}$, Jiancheng Wan $^{1}$, Ming Jiang ${ }^{1}$, Yimin $\mathrm{Ma}^{1}$ and Liang Feng ${ }^{1}$ \\ ${ }^{1}$ China Electric Power Research Institute, 100055, Beijing, China
}

\begin{abstract}
The merits and demerits of the movable balance-weight schemes in the existing tower crane are summarized and analyzed. The new design of rotatable balance-arm, latticed crane head, platform and rotational upper support is put forward for top of crane SXD50. The rotatable balance-arm is composed of two parallel truss structures, platform, luffing mechanism and balance-weight. The balance-arm can be pulled to rotate around the rotational upper support by luffing mechanism under amplitude control system. The forward torque is equaled to the backward torque from the balance-arm to realize the moment equilibrium of crane body during working. The luffing mechanism of balance-arm on the platform can be as a part of balanceweight. The finite element model of balance-arm and crane head is built and the calculated results prove the rotatable balancearm system reliable and the structure strength satisfies the requirement of design.
\end{abstract}

\section{Introduce}

Tower crane SXD50 has stationary balance-weight installed at the end of balance-arm[1]. No matter how the working range and lifting weight change, the bending moment is constant for the crane body. So the crane body has large cross-section to bear the maximum forward torque caused by load and the maximum backward torque by balance-weight[2].

The movable balance-weight of crane can generate equal backward torque during the operation to decrease the bending moment of crane body.

Currently, there are 4 kinds of movable balance-weight in tower crane[3-6]. (1) The self-adaptation balance-weight realized by crane-slider mechanism. (2) The forward and backward sway balance-weight realized by four bar linkage. (3) The movable balance-weight realized by reciprocating cycle wire rope. (4) Balance-weight pulled by independent tractor system along balancearm. The four methods mentioned above have various kinds of deficiencies and not adapted for the SXD50 crane.

Among the methods, crane-slider mechanism and four bar linkage need not add auxiliary power to drive. They have the following characteristics: simple structure and clear force-bearing state. But their range of motion is smaller. So, the maximum backward torque supplied can't balance the forward torque generated when loaded fully. In addition, using the two methods above, lifting-arm and balance-arm can't curl in the top of crane and demolish from center after construction, because of the auxiliary structure arrangement, such as link mechanism and linkage device.

In conclusion, the four methods mentioned above have various kinds of deficiencies. So, they are not adapted to the movable balance-weight design of crane SXD50. Therefore, for the crane construction characteristics of transmission line tower erection, developing a new type of movable balance-weight, which not only achieves the predetermined lifting ability, but also reduces the quality of total weight, is an important issue to be solved for the construction of high voltage transmission line.

99i9iIn this paper, a new type of movable balance-weight system is proposed, which is suitable for design of different cranes.

\section{The rotatable balance-arm design}

To form the design of rotatable balance-arm, the new type and structure are studied.

\subsection{The integrated pattern}

Based on the characteristics of crane SXD50, a series of new structures are proposed, including rotatable parallelogram balancearm, latticed head and platform.

Shown as Figure 1, there is small-sized vertical luffing mechanism is arranged on the platform of rotatable parallelogram balance-arm. The balance-weight is set under of platform. The balance-arm is pulled by luffing mechanism under amplitude control system in working, the movement of balance-arm makes the backward torque generated by balance-weight equal to the forward torque by working lifting-arm. This design can realize the goal of reducing the lopsided moment of crane body. 


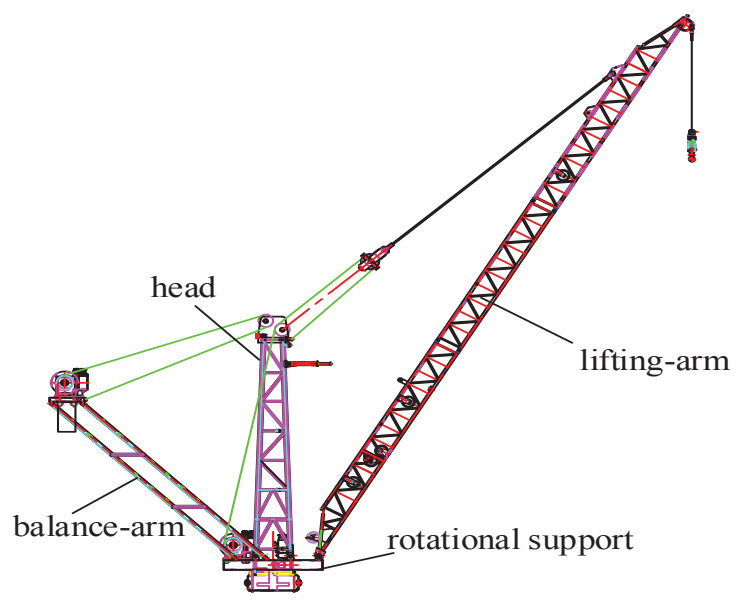

Figure 1. The pattern of rotatable balance-arm system

\subsection{Rotatable parallelogram balance-arm}

The rotatable balance-arm, which is located on the rotational support, includes two parallel truss structures, four connecting rods and platform. All parts are connected by pins. As shown in Figure 2, the parallelogram structure can remain the platform horizontal and make the luffing mechanism work normally. The minimum work angle of balance-bar is $7^{\circ}$, maximum is $87.5^{\circ}$.



1- Balance-arm, 2-Connect rod, 3-Platform, 4-Luffing mechanism, 5-Balance-weight

Figure 2. Rotatable parallelogram balance-arm

Shown as Figure 3, the upper truss is designed with opening downwards to assure the balance-arm not impact with the crane head. The lower truss has enough blank in the end to make the balance-weight pass through.



(a) upper truss

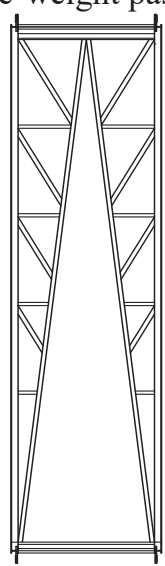

(b) lower truss

Figure 3. Balance-arm truss 
The platform (shown as Figure 4) is box-type structure. The luffing mechanism of balance-arm installed on the platform generates the backward torque with weight block under platform together.



Figure 4. Platform

\subsection{Crane head}

The head is latticed structure located in the center of rotational support. There is a limit putter on the head to avoid the impact of lifting-arm and balance-arm. The rotational assembly is shown as in Figure 5.

Figure 5. Crane head
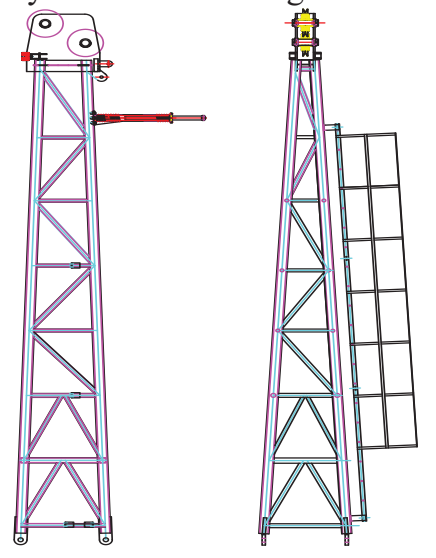

\subsection{Rotational upper support}

The rotational upper support is shown in Figure 6, and the hinged joint of lifting-arm end is arranged on the edge of rotational support. The slewing gear and jib lubbing mechanism is on the support.



1-Rotational upper support, 2-Hinged joint, 3- Slewing gear, 4-Jib lubbing mechanism

Figure 6. Rotational assembly

\section{Calculation of balance-arm structure}

To verify that the structure designed meets the strength requirement, the balance-arm and crane head are calculated here. The rotational support is small changed compared with the traditional type, so not check[7].

\subsection{Balance-arm}


The loads on the balance-arm include the weight of counter, platform, luffing mechanism, balance-arm, the wind load and the tension of wire rope. The wind load of balance-arm can be got as:

$$
F_{w}=C_{w} p_{w} \omega l h
$$

Here $C_{w}$ is wind coefficient $1.6, p_{w}$ is rated wind pressure $250 \mathrm{~Pa}, \omega$ is structure full ratio $1.0, l$ is length of balance-arm, $h$ is width of balance-arm.

The result of finite element analysis is shown in Figure 7. The maximum equivalent stress of balance-arm is 50MPa, which is much less than the allowable stress $[\sigma]_{\mathrm{Q} 345 \mathrm{~B}}=259.40 \mathrm{MPa}$. So the truss structure of balance-arm can meet the strength requirements.

\subsection{Tower head}

The tower head is mainly loaded with the tension force of lifting-arm and balance-arm. So there are 2 important work cases: 1) $3.125 \mathrm{t}$ load (overloading $25 \%$ ) at $21 \mathrm{~m}$ and the amplitude of balance-arm is the maximum $8 \mathrm{~m} ; 2$ ) $5 \mathrm{t}$ load (overloading $25 \%$ ) at $12.5 \mathrm{~m}$ and the amplitude of balance-arm is $8 \mathrm{~m}$.

The result is shown in Figure 8. The maximum equivalent stress of head is $70.8 \mathrm{MPa}$ in case $1,96.1 \mathrm{MPa}$ in case 2 , much less than the allowable stress. So the lifting-arm and the whole structure can meet the strength requirements.

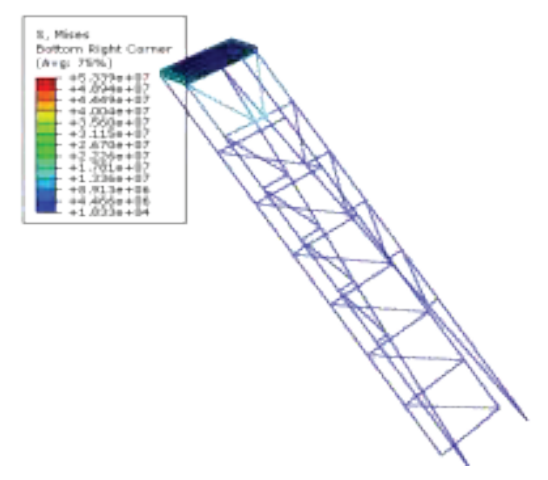

Figure 7. The result of balance-arm

Figure 8. The result of head

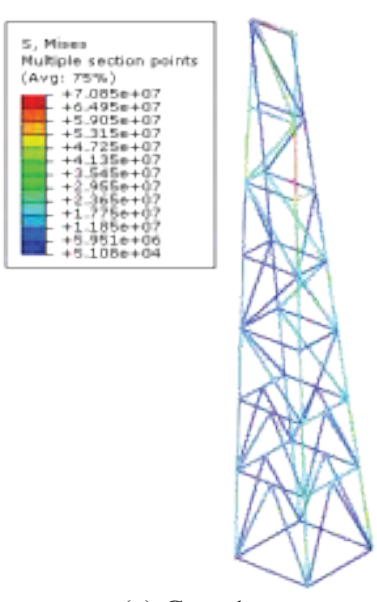

(a) Case 1



(b) Case 2

\section{Conclusion}

In this paper the new moveable balance-weight system is proposed based on crane SXD50.

Compared with the traditional type, the balance-weight can rotate around platform pulled by the luffing mechanism. The design can realize the moment equilibrium between the forward torque and the backward torque, which not only achieves the predetermined lifting ability, but also improves the force status of crane structure.

All the parts of moveable balance-weight system meet the strength requirements with a big redundancy. It is available to carry out the optimization research to reduce the total weight of crane.

\section{Acknowledgment}

This research was supported by Science and Technology Research Project of State Grid (Study on the key design technologies of mobile crane for tower erection in transmission line).

\section{References}


1. LI Qinglin. Scheme Selection of Holding Poles Erection for EHV Transmission Towers[J]. Electric Power Construction, 2007, 28(03): 29-33.

2. ZHANG Songhua, YU Qiu-an. Development and Application of LB-3 Crane[J]. Hubei Electric Power, 2010, $34(6)$ : 56-57.

3. ZHANG Ying, YAO Yan-an, ZHA Jianzhong. A Movable-Counterweights Method for Balancing of Mechanisms[J]. JOURNAL OF SHANGHAI JIAOTONG UNIVERSITY, 2006,40(12): 2039-2045.

4. ZHANG Mingqin, SUN Xiaoli, QU Zhenbo, SONG Chuanzeng, DONG Mingxiao. The Self-adaptation Regulating of Crane's Balanced Weight[J]. Machine Design and Research, 2003, 19(4): 44-46.

5. LIU Jiehai. Balance weighed mobilizable device of symmetrical pulling circulation luffing tower crane[J]. CONSTRUCTION MECHANIZATION, 2010(9): 64-66.

6. HOU Baojia, HUANG Qiong, TU Xunian. Optimized design of jib of derrick tower crane[J]. CONSTRUCTION MECHANIZATION, 2006(11): 24- 25.

7. WU Haorong, WANG Xiaoping, GOU Dunpan, LI Xiaoxiao. Optimization Design of Tower Crane Mast Based on ANSYS Zero-order Method[J]. Construction Machinery and Equipment, 2014, 45(2): 42-46. 